Journal of Computer Science 6 (2): 107-111, 2010

ISSN 1549-3636

(C) 2010 Science Publications

\title{
An Optimization of Design for S4-Duty Induction Motor Using Constraints Normalization Based Violation Technique
}

\author{
${ }^{1}$ R. Subramanian, ${ }^{2}$ S.N. Sivanandam and ${ }^{3}$ C. Vimalarani \\ ${ }^{1}$ Department of Electrical and Electronics Engineering, \\ ${ }^{3}$ Department of Computer Science and Engineering, \\ SNS College of Technology, Coimbatore-641 035, Tamilnadu, India \\ ${ }^{2}$ Department of Computer Science and Engineering \\ PSG College of Technology, Avinashi Road, Coimbatore-641 004
}

\begin{abstract}
Problem statement: Design of Induction motors is an engineering art and needs an extensive experience for obtaining an optimal design solution for a given design problem. An optimized GD ${ }^{2}$ value for the development of S4 Duty, cage induction motor to meet the specifications of a particular designated application (the location of application is kept as trade secret due to IP barrier) is proposed and validated by a physical model. Approach: The Genetic Algorithm (GA) is used to optimize inertia of rotating member as a single objective function for the designated application. A formulation based on the violations of normalized constraints is used here to transform the problem as unconstrained one. Results: The design variables for the developed model for the rating of $30 \mathrm{~W}$ for $\mathrm{S} 4$ duty operation were examined with the GA operators such as Initial population-15; two point crossover probability-0.8; mutation-0.05; number of generations-50; fitness scaling-rank; selection-Roulette wheel; Conclusion: The $\mathrm{GD}^{2}$ value obtained using the GAconstraints normalization technique and from the proto model developed are 26.24 and 33.04 respectively as against the specified value $40.75 \mathrm{~kg}-\mathrm{cm}^{2}$.
\end{abstract}

Key words: Induction motor, design optimization, genetic algorithm, constraints normalization

\section{INTRODUCTION}

In the recent past, many authors have devoted themselves to the design optimization of electrical machines. It is well known fact that the Induction motors are the most widely used (Subramanian et al., 2008) prime mover in industrial, agricultural, domestic and various commercial applications. The squirrel cage construction captures major share due to its simplicity, robustness and low cost which also attracts the industrialists belongs to process control sector. Besides the energy consumption the inertia of the rotating member ie., squirrel cage rotor is a major concern of a designer as it will affect the control and instrumentation process. Hence more focus given to optimize the GD2 value of the rotor.

The electromagnetic devices have continuous, discrete and in combination of both type of variables depends on their application. Many optimization problem techniques are discontinuities in search space and when conventional Non-Linear Programming (NLP) techniques are used, they would be computationally very expensive and time consuming. One such application uses such techniques is design of induction motors.

Owing to the technological advancement in the computation power of computers the Genetic Algorithm (GA) find an efficient tool not only in electrical machines design (Subramanian et al., 2008; Subramanian et al., 2009; Hisu et al., 2003; Wieczorek et al., 1998; Wurtz et al., 1997; Pillay et al., 1997; Liuzzi et al., 2003), but also in many other applications like structural designs, sensor-actuator locations. One of the most important advantages of the GA over the standard NLP techniques is that it is able to find the global minimum, instead of a local minimum and that the initial attempts with different starting point need not be close actual values.

This study presents a formulation and solution technique using GAs for the optimization of $\mathrm{GD}^{2}$ value of 30W AC 3 PHASE 415V, $50 \mathrm{~Hz}$, squirrel cage induction motor rotor for $\mathrm{S} 4-100 \%$ duty cycle operation and compares with proto model test results to validate the design optimization. To illustrate the applicability

Corresponding Author: R. Subramanian, Department of Electrical and Electronics Engineering, SNS College of Technology, Coimbatore-641 035, Tamilnadu, India Tel: +91-422-2590360/+91-98433 25903 
of the procedure few higher output ratings also have been taken and the results found suitable for the application designated.

Genetic algorithm: Charles Darwin has formulated the fundamental principle of natural selection as the main evolutionary tool. He put forward his ideas without the knowledge of the basic hereditary principles. In 1865 , Gregor Mendel discovered these hereditary principles by the experiments he carried out on peas. After Mendel's work genetics was developed. Morgan experimentally found that chromosomes were the carriers of hereditary information and that genes representing the hereditary factors were lined up on chromosomes. Darwin's natural selection theory and natural genetics remained unlinked until 1920s when it was proved that genetics and selection were in no way contrasting each other. Combinations of Darwin's and Mendel's ideas lead to the modern evolutionary theory (Subramanian et al., 2009).

Genetic algorithms are a search procedure emulating the mechanism of natural selection and genetics. The GA consists of three fundamental operators-selection, crossover and mutation (Karthik et al., 2008; 2009). Selection is a process by which individual strings are copied according to their fitness. The probability is directly proportional to the fitness of each string i.e., Darwin's theory of survival of the fittest. Crossover-members in the pool are mated at random according to the probability along each pair of strings either at single point or multipoint. Then, two new strings are created by exchanging all characters (Karthik et al., 2008). Using these two operators GA finds the more fit strings. In order to avoid local optimum and to find global solution, the GA offers the operator called Mutation (Karthikeyan et al., 2009; Sadish Sendil and Nagarajan 2009). This is the random alteration of a string position which is also chosen at random with minimum probability. This means that the values of crossover and mutation probabilities in the evolution process must be defined. Finally, if the constraints are satisfied, the optimal solution of the objective function can be evaluated quickly (Goldberg, 1989).

\section{MATERIALS AND METHODS}

Finding an optimized design parameters by searching vector $\mathrm{x}=\left[\mathrm{x}_{1} \ldots \mathrm{X}_{\mathrm{j} \ldots . .,} \mathrm{x}_{\mathrm{m}}\right]^{\mathrm{r}}$ representing a set of $m$ design variables, each of them bounded by $\mathrm{x}_{\mathrm{j}}^{\mathrm{L}} \leq \mathrm{x}_{\mathrm{i}} \leq \mathrm{x}_{\mathrm{j}}^{\mathrm{U}}, \mathrm{j}=1,2, \ldots \mathrm{m}$, so that the objective function $f(x)$ is minimized or maximized.

The aim of this work is to design and develop induction motors for the designated application in which the inertia of the rotating member is to be optimized as the rest of the parameters are given secondary importance. Hence the objective function is defined to evaluate the prime factor for which the design work is carried out besides other required parameters.

$\mathrm{F}(\mathrm{x})$ is designated as the objective function and here the inertia of the rotating member is to be limited as per the Table 1 specification:

$\mathrm{F}(\mathrm{x})=\mathrm{GD}^{2}=\left(\frac{\pi}{4}\right) \mathrm{D}^{4} \mathrm{~L}_{\mathrm{r}} \rho$

Where:

$\mathrm{G}=$ Weight of the rotating mass

$\rho=$ Weight density of the material $\left(\mathrm{kg} \mathrm{m}^{-3}\right)$

Mathematically, a typical optimal design problem can be stated as follows:

To find $x$ values for minimizing $f(x)$ subject to $\mathrm{g}_{\mathrm{i}}(\mathrm{x}) \leq 0 \mathrm{i}=1,2, \ldots . \mathrm{n}$ and $\mathrm{x}_{\mathrm{j}} \mathrm{L}_{\mathrm{i}} \mathrm{x}_{\mathrm{i}} \leq \mathrm{x}_{\mathrm{j}}^{\mathrm{U}} \mathrm{j}=1,2, \ldots \mathrm{m}$. Where $\mathrm{x}=\left[\mathrm{x}_{1} \ldots . \mathrm{X}_{\mathrm{j}} \ldots \ldots, \mathrm{x}_{\mathrm{m}}\right]^{\mathrm{r}}$ is a vector of design variables, $\mathrm{g}_{\mathrm{i}}(\mathrm{x})$ is the inequality constraints for the design problem. $\mathrm{X}_{\mathrm{j}}^{\mathrm{L}}$ and $\mathrm{x}_{\mathrm{j}}^{\mathrm{U}}$ are the lower and upper bounds of the design variables as listed in Table 2.

Table 1: Design specifications

\begin{tabular}{ll}
\hline Description & Value \\
\hline Nominal power-watts (rated) & 30 \\
Inertia $\left(\mathrm{GD}^{2}\right) \mathrm{kg} \cdot \mathrm{cm}^{2}(\mathrm{max})$ & 40.75 \\
Efficiency $(\%) \mathrm{min}$ & 35 \\
Power factor min & 0.46 \\
Duty rating & S4-100 \% \\
Type of motor & SQ. cage induction motor \\
Supply & AC, 3 PHASE, 415 V, 50 Hz \\
Nominal speed & $1400 \mathrm{RPM}$ \\
Starting torque-Ncm min & 175 \\
Form of construction & B14 SPECIAL \\
Motor pinion (No. of teeth) & 7 \\
Degree of protection and cooling & IP 65 and natural \\
Class of insulation & F \\
\hline
\end{tabular}

Table 2: Design variables with its bounds

\begin{tabular}{lll}
\hline & Search region & \\
\cline { 2 - 3 } Design parameter & Lower limit & Upper limit \\
\hline Gap density average & 0.375 & 0.525 \\
Periphery electric loading average & 10000 & 20000 \\
Number of conductors per slot & 309 & 696 \\
Stator slots & 20 & 28 \\
Rotor slots & 20 & 28 \\
Stator wire gauge & & \\
Rotor outer diameter blanking & 52 & 72 \\
Stator outer diameter & 87 & 126 \\
Stator core length & 20 & 70 \\
Rotor bore diameter & 15 & 25 \\
Air gap length & 0.26 & 0.32 \\
Stator slot height & 10.97 & 15.595 \\
Stator slot width & 5.74 & 7.36 \\
Rotor slot depth & 9.425 & 12.55 \\
Rotor slot width & 3.33 & 4.04 \\
Gap length & 0.25 & 0.35 \\
\hline
\end{tabular}


In practice, keeping the parameters $\mathrm{W}, \eta, \cos \Phi$ and $\mathrm{n}_{\mathrm{s}}$ are constant from the specification given and a set of D1, D2 and D3 corresponding other geometrical dimensions are picked up from the available spectrum of laminations to avoid cost implications on blanking and notching tool development.

Implementation of GA for optimization: The implementation of genetic algorithm, in general, may be carried out using the below mentioned steps:

Step 1: Define objective (fitness) function.

Step 2: Specify and encode design variables called chromosomes.

Step 3: Generate first population at random and find offspring.

Step 4: Evaluate the population by fitness function and check for possible violation of constraints.

Step 5: Start genetic (reproduction) process using appropriate strategy for each operator; Selection, Crossover, Mutation.

Step 6: Obtain new generation. Test convergence. If satisfied then stop else continue from step 4 .

For the design problem taken, the objective function is defined as in Eq. 1.

The design variables are specified along with its bounds in Table 2 and 8 bits are encoded for each continuous variables.

The parameters of GA operators were set as, Initial population-15; two point crossover probability-0.8; mutation-0.05; number of generations-50; fitness scaling-rank; selection-roulette wheel.

The constraints $\mathrm{g}_{\mathrm{i}}(\mathrm{x})$ can be written as follows:

$\mathrm{B}_{\text {ta } \mathrm{s}, \mathrm{r}} \leq \mathrm{B}_{\mathrm{tp} \mathrm{s,r}}$

$\mathrm{B}_{\mathrm{ca} \mathrm{s}, \mathrm{r}} \leq \mathrm{B}_{\mathrm{cp} \mathrm{s,r}}$

Here all the constraints cannot be directly described in terms of design variables; hence, they are implicit and their calculation requires analyzing the motor.

GA is ideally suited for unconstrained optimization problems (Pillay et al., 1997). As the present problem is a constrained optimization one, it is necessary to transform it into an unconstrained problem to solve it using GA (Sadish Sendil and Nagarajan, 2009). Since GA perform the search in parallel using population of points in the search space, a formulation based on the violations of normalized constraints is used. It is expressed as follows:

$$
\mathrm{B}_{\text {ta s,r }} / \mathrm{B}_{\text {tp s,r- }} 1 \leq 0 ; \mathrm{B}_{\text {ca s,r }} / \mathrm{B}_{\text {cp s,r- }} 1 \leq 0
$$

A violation coefficient $\mathrm{C}$ is computed in the following manner. If $\mathrm{g}_{\mathrm{i}}(\mathrm{x})>0$ then $\mathrm{C}_{\mathrm{i}}=\mathrm{g}_{\mathrm{i}}(\mathrm{x})$; if $\mathrm{g}_{\mathrm{i}}(\mathrm{x}) \leq 0$, then $\mathrm{C}_{\mathrm{i}}=0$ :

$$
\mathrm{C}=\sum_{\mathrm{i}=1}^{\mathrm{m}} \mathrm{c}_{\mathrm{i}}
$$

where, $\mathrm{m}=$ number of constraints.

Now, the modified objective function is:

$\phi(\mathrm{x})=\mathrm{f}(\mathrm{x})(1+\mathrm{KC})$

where, parameter $\mathrm{K}$ has to be judiciously selected depending on the required influence of a violated individual in the next generation.

A value of 20 was found suitable for the problem presented in this study.

It may seem logical to choose a very high value of $\mathrm{K}$ to ensure that no constraints are violated. However, too large values of $\mathrm{K}$ lead to numerical difficulties and local minima.

In the case taken for which specifications are given in Table $1, \mathrm{GD}^{2}$ value was given as primary objective function to be minimized subject to the following non linear inequality constraints which is found enough to the problem given and other parameters can be noted for information purpose:

- Maximum flux density in stator and rotor teeth $\leq 0.85 \mathrm{~T}$

- Maximum flux density in stator and rotor core $\leq 1.1 \mathrm{~T}$

- Maximum current density in stator conductor $\leq 4.75 \mathrm{~A} \mathrm{~mm}^{-2}$

- Maximum copper space factor $\leq 0.41$

- Minimum starting torque $\geq 175 \mathrm{~N}-\mathrm{cm}$

The $\Phi(\mathrm{x})$ has been converted into corresponding fitness value in order to have the best individual has maximum fitness. Goldberg (1989) and Subramanian et al. (2008) suggests that for minimization problems, $\Phi(\mathrm{x})$ should be subtracted from a larger constant, so that all the fitness values are non negative and individual get fitness values according to their actual merit. In the present work, the value of this constant is obtained by adding the maximum and minimum value of $\Phi(\mathrm{x})$. The expression for fitness becomes:

$\mathrm{Fi}=[\Phi(\mathrm{x}) \max +\Phi(\mathrm{x}) \min ]-\Phi \mathrm{i}(\mathrm{x})$

where, $\mathrm{Fi}=$ the fitness of the $i^{\text {th }}$ individual. Here the subscript ' $\mathrm{i}$ ' is introduced to indicate the individual in the population. 


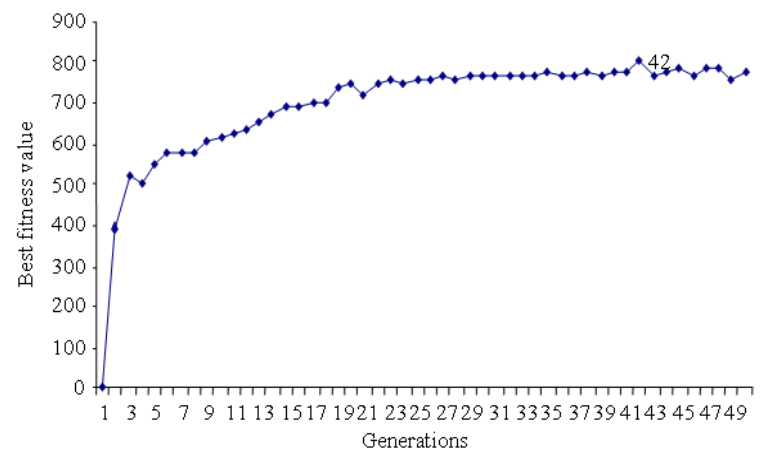

Fig. 1: Convergence of fitness function

Table 3 Comparison of performance values

\begin{tabular}{llcr}
\hline & $\begin{array}{l}\text { Specified/ } \\
\text { expected } \\
\text { value }\end{array}$ & $\begin{array}{l}\text { Values } \\
\text { obtained using } \\
\text { mathematical } \\
\text { model }\end{array}$ & $\begin{array}{l}\text { Values } \\
\text { obtained } \\
\text { on proto } \\
\text { model }\end{array}$ \\
Description & - & 30.00 & 31.600 \\
Nominal power watts (rated) & 30 & 62.00 & 62.000 \\
$\mathrm{D}(\mathrm{mm})$ & - & 29.00 & 36.500 \\
$\mathrm{~L}(\mathrm{~mm})$ & 40.75 & 26.24 & 33.040 \\
Inertia $\left(\mathrm{G} \mathrm{D}^{2)} \mathrm{kg} \cdot \mathrm{cm}^{2}(\mathrm{max})\right.$ & 35 & 39.47 & 38.000 \\
Efficiency in \% $(\mathrm{min})$ & 0.46 & 0.41 & 0.610 \\
Power factor $(\mathrm{min})$ & 1400 & 1385.00 & 1415.000 \\
Nominal speed in RPM & 175 & 192.00 & 179.500 \\
Starting torque-N-cm & 0.259 & 0.26 & 0.189 \\
Line current in A & $\mathrm{F}\left(110^{\circ} \mathrm{C}\right)$ & 76.00 & 68.000 \\
Temperature rise $\left({ }^{\circ} \mathrm{C}\right)$ & & &
\end{tabular}

Based on the trials made, the best fitness value found to be converged at 42 nd generation out of 50 generations attempted shown in Fig. 1. The optimized design parameters along with the performance values obtained based on the analytical procedure using equivalent circuit parameters are shown in Table 3 and compared with the actual test values conducted on proto model for validation of the design output.

\section{RESULTS}

Table 3 gives a comparison between specified values and mathematical model obtained using MATLAB plus analytical procedure. The algorithm with different combinations of GA operators was performed and found that with the below mentioned parameters best results were achieved in the search region provided in Table 2 which was found more suitable for this application. Further in order to validate the design output which was verified by analytical procedure a proto model of which the lamination layout is shown in Fig. 2 was fabricated with great care in the material and process.

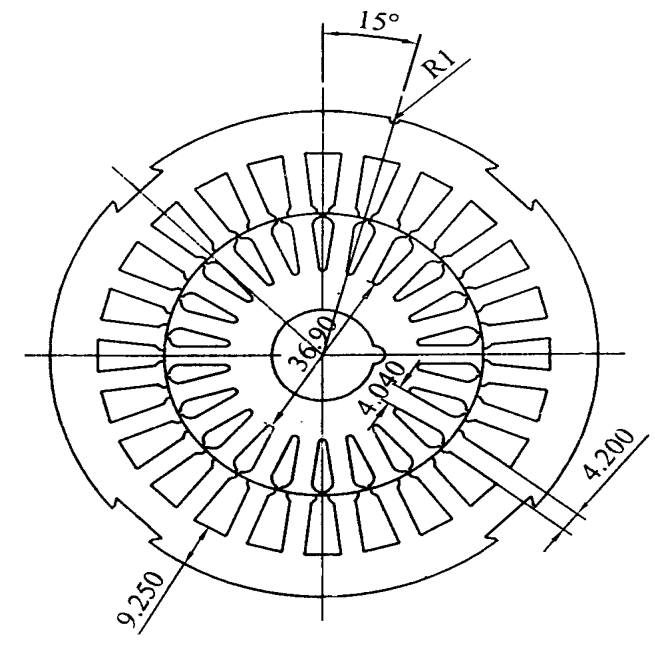

Fig. 2: Layout of lamination of induction motor

\section{DISCUSSION}

The $\mathrm{GD}^{2}$ value calculated from the analytical procedure is $26.24 \mathrm{~kg}-\mathrm{cm}^{2}$ and measured on the prototype model is $33.04 \mathrm{~kg}-\mathrm{cm}^{2}$ as against the specified value $40.75 \mathrm{~kg}-\mathrm{cm}^{2}$ and hence in both the cases, it is with in the limits. Further, the performance parameters such as Efficiency, Power Factor, Speed, Starting Torque, Line Current, Winding Temperature Rise are 38\%, 0.61, $1415 \mathrm{rpm} 179.5 \mathrm{~N}-\mathrm{cm} 0.189 \mathrm{~A}$, $68^{\circ} \mathrm{C}$ from the results of proto model and $39.5 \%, 0.41$, $1385 \mathrm{rpm} 192 \mathrm{~N}-\mathrm{cm}, 0.260 \mathrm{~A} 76^{\circ} \mathrm{C}$ from the results of analytical procedure against the specified values of $35 \%, 0.46,1400 \mathrm{rpm} 175 \mathrm{~N}-\mathrm{cm} 0.259 \mathrm{~A}, 110^{\circ} \mathrm{C}$ respectively. Even though the power factor and speed values does not satisfies the requirement, from the test results it is observed that the performance values of proto model is satisfying the specified values. However, the cost of the machine fabricated is found to be $20 \%$ higher as the active materials used are of higher grade and this can be brought down by mass production. Since the primary objective given is $\mathrm{GD}^{2}$ value, the cost parameter as of now becomes secondary importance.

\section{CONCLUSION}

A design work carried out by using constraints normalization based violation technique in the design optimization by GA is presented in this study. It is observed that with the fair population size and generations the design parameters found to be converged in a reasonable time and analytical procedure provides a balance between time and expected results. As this problem is of minimization 
type, the same algorithm can be used with minor modifications for maximization type requirements such as efficiency, torque or multiple objective types.

\section{ACKNOWLEDGEMENT}

The researchers wish to thank M/s PSG Industrial Institute, Coimbatore for carrying out development work and M/s Small Industries Testing and Research Centre (SiTarc), Coimbatore for research and testing work at their premises. The authors also wish to thank $\mathrm{M} / \mathrm{s}$ SNS College of Technology, Coimbatore for providing infrastructure facility to do optimization work.

\section{REFERENCES}

Goldberg, D.E., 1989. Genetic Algorithms in Search, Optimization and Machine Learning. 1st Edn., Addison-Wesley Publishing Company, New York, USA., ISBN: 0201157675, pp: 36-90.

Karthik, S., V.P. Arunachalam and T. Ravichandran, 2008. A comparative study of various IP trace back strategies and simulation of IP trace back. Asian J. Inform. Technol., 7: 454-458. http://www.medwelljournals.com/fulltext/ajit/2008 1454-458.pdf

Karthik, S., V.P. Arunachalam and T. Ravichandran, 2008. Multi directional geographical traceback with in directions generalization. J. Comput. Sci., 4: 646-651. http://www.scipub.org/fulltext/jcs/jcs48646-651.pdf

Karthik. S., V.P. Arunachalam and T. Ravichandran, 2006. Implementation and application of location discovery in enterprise-based wireless networks. Natl. J. Eng., 8: 22-26.

Karthik. S., V.P. Arunachalam and T. Ravichandran, 2009. Analyzing interaction between denial of service (dos) attacks and threats. Int. J. Soft Computing., $\quad 4: \quad 68-75 . \quad$ DOI: 10.3923/ijscomp.2009.68.75

Karthik. S., V.P. Arunachalam and R.M.Bhavdharini, 2008. Analyzing interaction between denial of service (dos) attacks and threats. Proceeding of the IEEE International Conference on Computing, Communication and Networking, Dec. 18-20, IEEE Xplore Press, USA., pp: 1-9. DOI: 10.1109/ICCCNET.2008.4787663

Karthikeyan. N., V. Palanisamy and K. Duraiswamy, 2009. Reducing broadcast overhead using clustering based broadcast mechanism in mobile ad hoc network. J. Comput. Sci., 5: 548-556. http://www.scipub.org/fulltext/jcs/jcs58548-556.pdf
Hisu, L.Y., M.C. Tsai and C.C Huang, 2003. Efficiency optimization of brushless permanent magnet motors using penalty genetic algorithms. Proceeding of the IEEE International Conference on Electric Machines and Drives, June 1-4, IEEE Xplore Press, USA., pp: 365-369. http://ieeexplore.ieee.org/xpl/freeabs_all.jsp?tp=\&a rnumber $=1211289$ \&isnumber $=27264$

Liuzzi, G., S. Lucidi, F. Parasiliti and M. Villani, 2003. Multiobjective optimization techniques for the design of induction motors. IEEE Trans. Magnet., 39: 1261-1264. DOI: 10.1109/TMAG.2003.810193

Pillay, P., R. Nolan and T. Haque, 1997. Application of genetic algorithm to motor parameter determination for transient torque calculations. IEEE Trans. Ind. Appl., 33: 1273-1282. DOI: $10.1109 / 28.633806$

Sadish, S.M. and N. Nagarajan, 2009. Analyzing the peer to peer traffic aggregation using an optimized method. J. Comput. Sci., 5: 738-744. http://www.scipub.org/fulltext/jcs/jcs510738744.pdf

Subramanian, R., S.N. Sivanandam and C. Vimala Rani, 2008. An investigation on the design optimization techniques of electrical machines using genetic algorithm. Int. J. Highly Reli. Elect. Syst. 1: 77-82.

Subramanian, R., S.N. Sivanandam and C. Vimala Rani, 2009. Effect of winding wire insulation on the reliability of squirrel cage submersible induction motor for inverter duty operation-a case study. Int. J. Appl. Eng. Res., 4: 1823-1831. http://www.ripublication.com/ijaerv3/ijearv4n9_20 .pdf

Wieczorek, J.P., G. Ozdeir and M. Zbigniew, 1998. An evolutionary algorithm for the optimal design of induction motors. IEEE Trans. Magn., 34: 3882-3887. DOI: $10.1109 / 20.728298$

Wurtz, F., M. Richomme, J. Bigeon and J.C. Sabonnadiere, 1997. A few results for using genetic algorithms in the design of electrical machines. IEEE Trans. Magn., 33: 1892-1895. DOI: 10.1109/20.582656 